\title{
Summary of the Diamond Resource Potential and Production Capacity Assessment of Guinea
}

\section{The Kimberley Process}

In May of 2000, a meeting was convened in Kimberley, South Africa, by representatives of the diamond industry and leaders of African governments to develop a certification process intended to assure that export shipments of rough diamonds were free of conflict concerns. Outcomes of the meeting were formally supported later in December of 2000 by the United Nations in a resolution adopted by the General Assembly. By 2002, the Kimberley Process Certification Scheme (KPCS) was ratified and signed by diamond-producing and diamond-importing countries. As of August 2012, the Kimberley Process (KP) had 51 participants representing 77 countries.

\section{Administrative Decision on Guinea}

During the Seventh Annual Plenary Session of the KPCS held in Swakopmund, Namibia, in November 2009, an Administrative Decision (AD) on Guinea was adopted. The Swakopmund AD was the result of concerns relating to Guinea's significant increase in diamond exports between the years 2006 and 2008, in which production spiked from 473,862 carats in 2006 to 1,018,722 carats in 2007 and 3,098,490 carats in 2008 (Kimberley Process Rough Diamond Statistics, 2006, 2007, 2008). The AD requested that Guinean authorities relaunch a system of internal controls, including stopping any exports of rough diamonds of suspicious origin (KPCS Secretariat, 2009).

\section{Field Assessment}

With the passing of the AD, the Plenary agreed that further efforts should be made to assess Guinea's diamond production capacity (KPCS Secretariat, 2009). In support of this objective, the U.S. Geological Survey (USGS) partnered with the Kimberley Process Working Group of Diamond Experts (WGDE) and Guinea's Ministry of Mines and Geology (MMG) to conduct a field campaign in Guinea from April 24 through May 2, 2010. The field team was composed of Mark Van Bockstael of the WGDE, Peter Chirico of the USGS, and several geologists from the MMG.
The team visited diamond mining sites in western Guinea's Kindia, Forécariah, Coyah, and Télimélé Prefectures, in which the Guinean government identified newly discovered deposits mined by artisans (fig. 1). Several mining sites within the Kissidougou Prefecture in southeastern Guinea were also visited as part of this study. Geologic and geomorphic information on the diamond deposits was collected at each site. The fieldwork conducted during this trip served as a means of acquiring critical data needed to conduct a full assessment of diamond resources and production capacity.

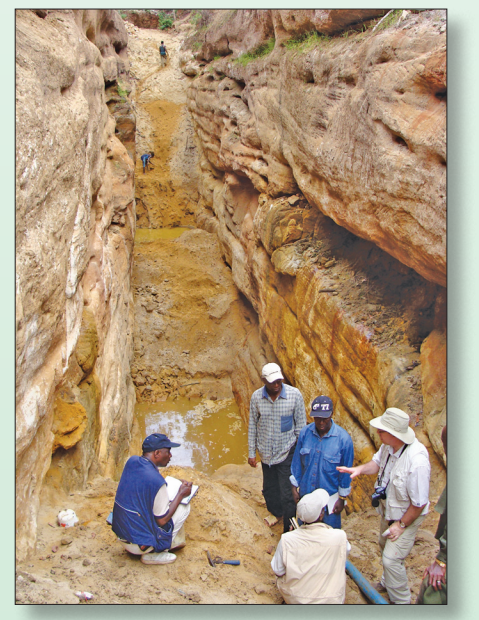

Figure 1. A bedrock fracture/paleoplacer deposit actively mined by artisans at Férékouré in the Kindia Prefecture of western Guinea.

\section{Training}

A team from the USGS made a return trip to Guinea from May 31 through June 4, 2011. The purpose of this trip was threefold. First, the results of the report drafted after the 2010 visit were presented to members of the MMG and representatives of civil society organizations such as the International Trade Centre for Development (CECIDE) and the Confédération Nationale des Diamantaires et Orpailleurs de Guinée (CONADOG), with the support from Partnership Africa Canada (PAC), the U.S. Embassy, and the U.S. Agency for International Development (USAID). Second, the methodology used by the USGS to conduct the diamond resource

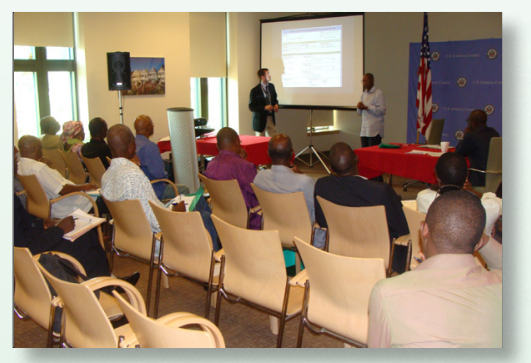

Figure 2. A presentation given by the USGS for civil society organization representatives on the methodology used to conduct resource assessments, June 2011, Conakry, Guinea.

potential and production capacity assessments of Guinea was explained in detail to the MMG and civil society representatives (fig. 2). Third, the USGS demonstrated methods for conducting fieldwork and data gathering techniques to members of the MMG and civil society organizations during a trip to the Forécariah Prefecture.

\section{Multistakeholder Cooperation}

To address the lack of necessary data, this effort represents a new direction in the KP's monitoring and evaluation of diamond resources. Multiple stakeholders at several levels of government and civil society and industry cooperated to conduct fieldwork and gather data necessary to produce a countrywide diamond assessment. This cooperative agreement is conducted with international support from the KP and with support from the national government for the organizations CECIDE and CONADOG, which in turn represent artisanal mining interests, with the final partner being artisanal miners at the local level.

In March of 2012, further fieldwork was conducted by a team composed of Mamadou Diaby, Coordinator of the Programme Exploitation Artisanale de Diamant and the Kimberley Process at CECIDE; Thierno Amadou Diallo, Executive Director General of the Brigade Antifraude des Matières Précieuses; and Mahmoud Sano, Chef de Section Exploitation Artisanale Diamant at the MMG. The team visited five artisanal diamond mining sites in the Kindia and Télimélé 
Prefectures. Later that month, the USGS returned and conducted a joint fieldwork mission with geologists from CECIDE and the MMG and visited seven artisanal diamond mining sites in the Forécariah and Coyah Prefectures. The final fieldwork mission was conducted in May 2012 by the Guinean team. Seventeen artisanal diamond mining sites in the intensively mined Macenta and Kérouané Prefectures of southeastern Guinea were visited during this mission (fig. 3).

\section{Diamond Resource Potential}

To conduct the assessment, Guinea's diamond deposits were first separated into five "diamondiferous regions," in order to more accurately reflect the geomorphological parameters of each deposit. Hydrologic and geomorphic models were then developed for each of the regions. The resource potential was first calculated for the individual regions using the following variables: estimated grades, gravel thicknesses, and surface areas of the alluvial flats and terraces. The volume of the diamondiferous gravel was calculated by multiplying the average gravel thickness by the surface area of the alluvial flats and terraces. Three-quarters of the volume of gravel was multiplied by the "basic" grade, while the remaining quarter of the volume was multiplied by the higher "concentration" grade.

The results for each region were then totaled, amounting to 60 million carats. The next step was to subtract the number of carats that had already been mined, which was estimated to be 20 million carats. Once subtracted from the total estimated reserves, the revised total diamond resource came to approximately 40 million carats.

\section{Production Capacity Assessment}

The diamond production capacity was then estimated by a mathematical formula, using the following variables: the volume of gravel mined per person per day, estimated to be 0.14 cubic meter; the average gravel grade of the deposits, estimated to vary regionally from 0.08 to 0.2 carats per cubic meter; the number of days worked per year, estimated to be 216; the total number of active artisanal miners, estimated to be 100,000 ; and the total industrial production, estimated to be 100,000 carats. Applying these variables to the equation resulted in a production capacity of 600,000 carats per year.

Multiple variables, the values of which were calculated from historical records and field data, were utilized to arrive at the production capacity estimates. It is possible that the values of one or more of the variables used in the equation may overestimate or underestimate the situation on the ground. However, due to the significant amount of data collected during the multiple fieldwork missions and the exhaustive background literature review, the total production capacity likely does not fall below or above 20 percent of the estimated 600,000 carats. A realistic range of production

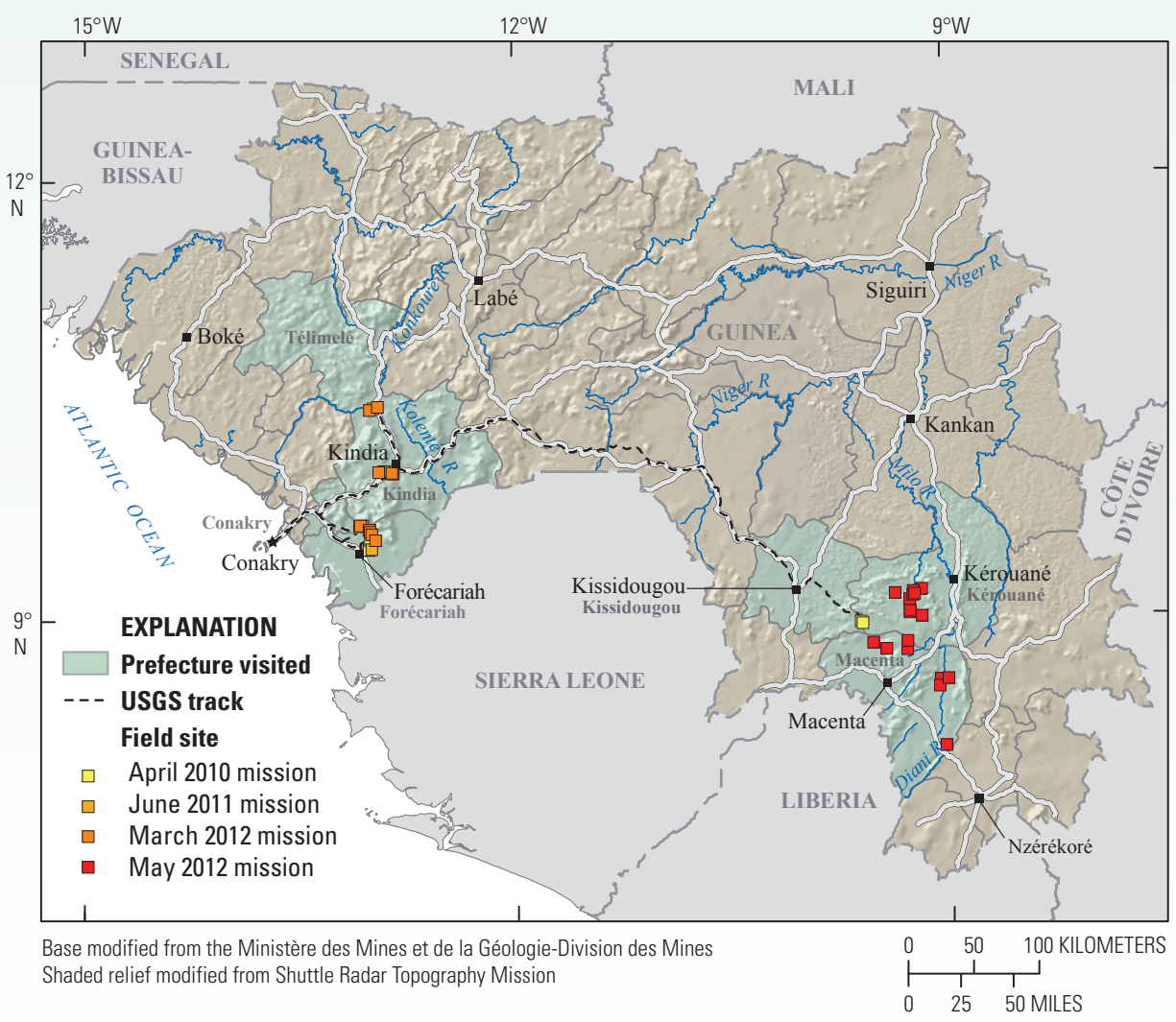

Figure 3. Guinean sites visited during each of the fieldwork missions.

for Guinea therefore is 480,000 to 720,000 carats per year.

\section{Conclusion}

Although preliminary results have been obtained, it is important to note that artisanal diamond mining is a highly dynamic sector, and therefore it is challenging to make firm production calculations. The results estimated in this study, however, were developed through an examination of all available information concerning Guinea's diamond deposits and therefore is the best available guide to assessing Guinea's diamond deposits. While data gaps remain, this assessment provides a reliable baseline from which other studies may be conducted. The summary of the information here is also a step toward greater information transparency with respect to alluvial diamond resources.

\section{References Cited}

Kimberley Process Rough Diamond Statistics, 2006, Annual global summary-2006 production, imports, exports and KPC counts: Kimberley Process Rough Diamond Statistics Web site, accessed October 15, 2012, at https://kimberleyprocessstatistics.org/static/ pdfs/public_statistics/2006/2006Global Summary.pdf.

Kimberley Process Rough Diamond Statistics, 2007, Annual global summary—2007 production, imports, exports and KPC counts: Kimberley Process Rough Diamond Statistics Web site, accessed October 15, 2012, at https://kimberleyprocessstatistics.org/static/ pdfs/public_statistics/2007/2007Global Summary.pdf.

Kimberley Process Rough Diamond Statistics, 2008, Annual global summary-2008 production, imports, exports and KPC counts: Kimberley Process Rough Diamond Statistics Web site, accessed October 15, 2012, at https://kimberleyprocessstatistics.org/static/ pdfs/public_statistics/2008/2008Global Summary.pdf.

Kimberley Process Certification Scheme (KPCS) Secretariat, 2009, Administrative Decision: Kimberley Process Plenary Session, November 5, 2009, Swakopmund, Namibia, 3 p., accessed October 15, 2012, at http://kimberleyprocess.com/web/ kimberley-process/administrative-decisions.

\section{Additional Information}

Peter G. Chirico, pchirico@usgs.gov Katherine C. Malpeli, kmalpeli@usgs.gov 12201 Sunrise Valley Drive National Center, MS 926A Reston, VA 20192 